American J. of Engineering and Applied Sciences 1 (4): 358-367, 2008

ISSN 1941-7020

(C) 2008 Science Publications

\title{
Optimal Production Planning of Electricity from Coal-Fired Power Plant Networks under Environmental Considerations
}

\author{
${ }^{1}$ Habib H. Al-Ali, ${ }^{2}$ Yousef Saif, ${ }^{2}$ Ali Elkamel and ${ }^{3}$ Ali Lohi \\ ${ }^{1}$ Department of Chemical Engineering, King Fahd University of Petroleum and Minerals, Saudi Arabia \\ ${ }^{2}$ Department Chemical Engineering, University of Waterloo, Waterloo ON N2L3G1 Canada \\ ${ }^{3}$ Department of Chemical Engineering, Ryerson University, Toronto ON M5B2K3 Canada
}

\begin{abstract}
In this study, electricity production from a network of coal power plants and under environmental constraints is considered. Several pollutants are incorporated into the decision planning process including nitrogen oxides $\left(\mathrm{NO}_{\mathrm{x}}\right)$, sulfur oxides $\left(\mathrm{SO}_{\mathrm{x}}\right)$ and mercury $(\mathrm{Hg})$. A Nonconvex Mixed Integer Nonlinear Programming (MINLP) model was first developed to assist in the evaluation process. An exact linearization of the nonconvex terms was then derived to reformulate the MINLP model into a mixed integer linear program (MILP). Several scenarios of electricity production planning and emission reduction targets are analyzed on a representative case study.
\end{abstract}

Key words: Coal power plants, multi-pollutant emissions, optimal electricity production planning

\section{INTRODUCTION}

Coal represents an abundant source of fossil fuel that helps energy supply in several countries including Canada. In the Ontario province, $27 \%$ of electricity production is supplied from coal-fired power plants. Coal prices are comparatively cheaper than other fossil fuels (e.g., natural gas, oil). The combustion processes of coal in power plants produce large amounts of emissions that have adverse effects on the environment and the public health. Abatement of pollutants resulting from coal combustion has put operational restrictions on coal-fired power plants. Therefore, there is a crucial need to optimize and/or redesign the electricity production system from coal power plants while minimizing airborne emissions to comply with environmental regulations $\mathrm{s}^{[1-4]}$.

Gaseous $\mathrm{SO}_{\mathrm{x}}$ (e.g., $\mathrm{SO}_{2}$ ) and $\mathrm{NO}_{\mathrm{x}}$ emissions have direct threat on human health due to their role as precursors which lead to the formation of secondary particulates, a constituent of particulate matter. Fine particles can reach very sensitive parts of the lung which may cause serious health problems. Besides, the reaction of $\mathrm{SO}_{\mathrm{x}}$ and $\mathrm{NO}_{\mathrm{x}}$ emissions with water, oxygen and oxidants in air leads to the formation of various acidic compounds. These compounds normally deposit in wet forms (e.g., acidic rain, fog) and in dry conditions (e.g., acidic gases, particulate). Acid deposition leads to negative changes in the environment such as altering water $\mathrm{pH}$, releasing Aluminum from soil and damaging plant tissues. Mercury can be in the form of element, ion, or particulate as a result of coal combustion. Exposure to $\mathrm{Hg}$ compounds lead to impaired growth and development, behavioral abnormality and death. The aforementioned risks have led the Environmental Protection Agency (EPA) to set up strict regulations on coal-fired power plant emissions $^{[5]}$.

In response to the Clean Air Act Amendment 1990, several mitigation policies were proposed to cope with coal-fired power plant emissions. These may include power plant efficiency enhancement, fuel balancing, shifting toward other type of fuels (e.g., natural gas), installation of capture processes for the target pollutants and increasing the electricity production from renewable energy technologies and nuclear plants. These strategies require intensive evaluations within the scope of a single power plant and a fleet wide power generation system ${ }^{[5,6]}$.

Coal power plants essentially burn coal in a boiler to generate steam. Afterwards, the steam under high pressure and temperature drives gas turbines with electrical generators to produce electricity. The thermal efficiency of these plants ranges between $35-47 \%$ for subcritical plants and supercritical plants, respectively. Integrated Gasification Combined Cycle (IGCC) plants represent the state of the art in electricity generation with coal fuel. These plants require the production of syngas in a gasification unit. Several clean up processes can be integrated to clean $\mathrm{CO}_{2}$ and sulfur compounds

Corresponding Author: Habib H. Al-Ali, Department of Chemical Engineering, KFUPM, P.O. Box 1535, Dhahran 31261, Saudi Arabia 
prior to the combustion process. After the combustion of syngas, the superheated gas runs gas turbine units. The exhaust from these units can generate steam that further runs steam turbine units to produce more electricity. In general, the IGCC plants are more efficient than PC plants and have lower emissions, however, the IGCC plants are still more expensive ${ }^{[4,7]}$.

Flue gas treatment equipments normally exist in the chemical and petrochemical industries. These equipments can also be applied for the treatment of the flue gas in power plants. Due to the differences in the production scale, flue gas characteristics and the required treatment in power plants, several technologies were developed to achieve the emission reduction in power plants. These technologies were either developed to capture a single pollutant or multipollutant present in the flue gas streams. A comprehensive review of these technologies was reported in a thorough study prepared by $(\text { EPA })^{[8]}$.

The current research presents a discrete optimal production planning model for electricity generation from a network of coal-fired power plants. The optimization model is formulated as an MINLP which decides upon the optimal operation of a power generation network and the selection of capture processes of multipollutant present in the flue gas streams. Different scenarios are covered to study the effects of increasing electricity demand and emission reduction on the optimal operation of the network. Next section presents literature review of different models related to the power generation. This is followed by the problem statement and a description of the power generation network superstructure. Next, the MINLP model is given to describe the mathematical programming formulation. Afterwards, different scenarios are presented to analyze the results of the model. A discussion and possible extensions are given in the last section.

Literature review: The environmental impact of power generation with coal-based fuels has driven extensive research to retrofit and build new plants with minimum airborne gas emissions. The trend of the studies shows improvement of single plants and network of power plants. A systematic modeling framework that provides preliminary cost and performance assessments of coalfired power plants was developed under the name of Integrated Environmental Control Model (IECM) at the center for energy and environmental studies, Carnegie Mellon University. The software simulates the performance of coal-fired power plants with the consideration of multipollutant emission control technologies ${ }^{[7]}$.

Optimal utilization of coal fuel with a fleet of coalfired power plant was presented as a Linear Programming (LP) model. The coal supply points were linked to washing/cleaning plants, power plants and finally the demand market. This formulation of the network gives assessment of the viability of coal as a fuel taking into consideration $\mathrm{CO}_{2}$ emission constraints. The formulation of the mathematical program presents an example of the transportation problem and the applicability of the LP model was demonstrated on India $^{[9]}$.

A linear programming model is formulated to assist the effects of natural gas fuel, different power generation technologies and capacity and the cost of $\mathrm{CO}_{2}$ sequestration on the carbon capture and storage mitigation viability for a network of coal-fired power plants. The sensitivity analysis shows that the natural gas being at a lower price eliminates the CCS mitigation. It also shows that when $\mathrm{CO}_{2}$ has an economical value (e.g., enhanced oil recovery applications) and very low coal prices, CCS becomes an attractive to maintain constrained emission limitations. However, the assessment does not provide solid judgment about the effects of other technologies on $\mathrm{CCS}^{[10]}$. It also suggests that other pollutants such as $\mathrm{NO}_{\mathrm{x}}, \mathrm{SO}_{\mathrm{x}}$ and $\mathrm{Hg}$ will have influence on the CCS mitigation. Fluctuation of electricity demand from a baseload demand, operation of existing plants, investment and operation of new technologies was studied to perform evaluation of CCS mitigation under different $\mathrm{CO}_{2}$ emission constraints. Also, the investment of new technologies such as IGCC was considered in the model. The results show pronounced effect of electricity variations on the optimal mitigation of $\mathrm{CO}_{2}$ emission $^{[11]}$.

Carbon capture processes consume significant amount of energy that should be supplied from the plant itself or from an external source. This energy penalty will in general affect the plant output and the electricity cost. To compromise with the electricity consumption through capture processes, several technologies such as IGCC, NGCC and renewable sources as well as PC were integrated with coal-fired plants to supply the electricity demand. Therefore, the total power production from a mix of technologies was studied to analyze the effect of capture processes on the Cost Of Electricity $(\mathrm{COE})^{[12]}$. A study considered the previous issues shows that the power generation mix and fuel prices have strong impact on the COE. In general, with lower cost of coal compared with natural gas and 
improving the carbon capture processes, $\mathrm{PC}$ plants will be competitive. With an increase of $\mathrm{CO}_{2}$ emission restrictions, the COE will likely to increase over time ${ }^{[13]}$.

Optimization of a network with discrete decisions helps to compare different alternatives of electricity generation design with respect to a given criterion (e.g., economical objective, emission reductions). This modeling approach has be been adopted to optimize the supply chain problem of a fleet wide generation of power plants with environmental consideration. The coal-fired plants, natural gas plants and renewable energy plants were optimized to supply a fixed demand while minimizing $\mathrm{CO}_{2}$ emissions. The model takes into consideration electricity capacity expansion and $\mathrm{CO}_{2}$ capture and sequestration. A case study of Ontario Power Generation (OPG) is considered as an application of the mathematical programming model ${ }^{[14]}$. Production planning encompasses prediction of future events which are associated with uncertainty. Optimal electricity production planning resembles conditions of uncertain product demand and facility production throughput. Forecasting of peak and base load electricity demands was modeled based on linear/multiple regression techniques to predict long term electricity needs ${ }^{[15]}$. Uncertainty of fuel prices (e.g. coal, natural gas) and electricity demand were considered as random variables in a robust mathematical program to analyze optimal electricity from a power generation fleet that rely on fossil fuel power plant (e.g., coal, natural gas) and nuclear power plants. The robust formulation takes into consideration $\mathrm{CO}_{2}$ reduction target. Another stochastic MILP formulation considered power planning expansion formulation from fossil fuel and hydroelectric power generation network ${ }^{[16]}$. A different modeling approach of power production planning and facility expansion of mixed power plants is formulated as a multiperiod mathematical programming formulation. The model considered different mix of fossil fuel power plants with $\mathrm{CO}_{2}$ capture processes, renewable energy plants and nuclear plants. In addition, several $\mathrm{CO}_{2}$ reduction target and increased electricity demand is embedded in the formulation ${ }^{[15]}$. A decomposition algorithm for the multiperiod energy supply system was presented to reduce the computational time ${ }^{[17]}$. In general, the stochastic and multiperiod models provide more flexibility in presenting the electricity production planning and facility expansion problem compared with the deterministic static models.

Electricity production planning from existing power plants, emissions capture and minimization and optimal electricity generation expansion normally poses multiple conflicts of objectives. Multiple objectivebased mathematical programming models give tools to describe these conditions ${ }^{[18-20]}$. This approach allows evaluation of incompatible measures (e.g., economical, environmental, social etc.) which in turn provides a compromise solution. Another advantage with the approach is the minimization of the environmental impact of emissions rather than giving upper bounds on their limitations. The framework of multiple objective optimization has been applied to model the optimal electricity production planning, capacity expansion and emission reductions in power plants.

Problem statement: It is assumed that the power generation network is composed of coal-fired power plants. This network supplies a predetermined electricity demand. Further, it is assumed that coal is the fuel consumed to run the power plants. During the combustion process, the hot gas which runs the gas turbines contains $\mathrm{SO}_{\mathrm{x}}, \mathrm{NO}_{\mathrm{x}}$ and $\mathrm{Hg}$. The exhaust gases can be captured or emitted to the atmosphere. The main goal of this study is to determine the optimal operation of fleet wide coal-fired power plants to satisfy the electricity demand while maintaining acceptable emission levels to comply with environmental constraints.

Problem representation: The problem can be viewed as several coal-fired power stations, cs, which have several coal-fired power plants, i, that supply regional electricity demand. Over every boiler at a given power plant, $i$, it is assumed that several capture processes, $j$, that may exist to reduce the emissions of pollutants, $\mathrm{k}$, to the acceptable level. Figure 1 shows the representation of the coal-fired power plants network.

It is worth pointing out that the superstructure representation is flexible to include other fossil and nonfossil power plants.

Mathematical programming formulation: Discrete variables help to model the existence of unit operations in process synthesis problems. 0/1 binary variables, $\mathrm{Y}_{\mathrm{cs}, \mathrm{i}, \mathrm{j}}$, are introduced in the model formulation to define the existence of capture process $j$ on a boiler $i$ at a coal power station cs. Every boiler $i$ at a coal station cs produces electricity, $E_{\mathrm{cs}, \mathrm{i}}$, as a result of coal combustion in the plant. The objective function is defined as to minimize the total annualized cost TAC as follows: 


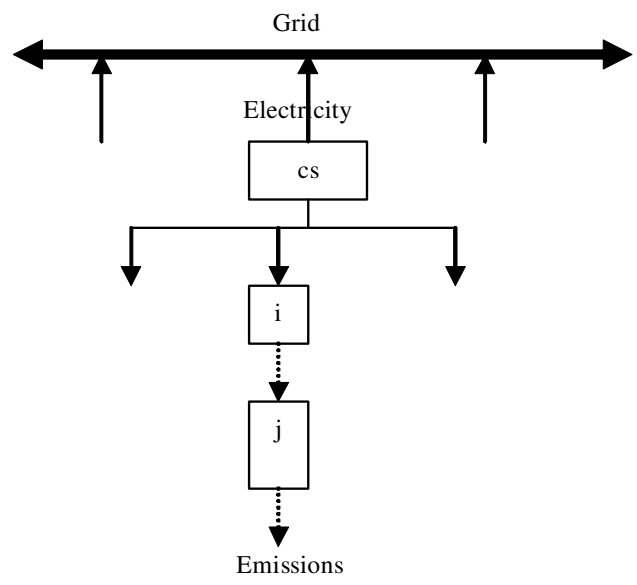

Fig. 1: Superstructure representation of coal-fired power plants

$$
\begin{aligned}
& \mathrm{TAC}=\sum_{\mathrm{cs}} \sum_{\mathrm{i}} \mathrm{C}_{\mathrm{css}, \mathrm{i}}^{\mathrm{Eop}} \mathrm{E}_{\mathrm{cs}, \mathrm{i}}+ \\
& \sum_{\mathrm{cs}} \sum_{\mathrm{i}} \sum_{\mathrm{j}}\left(\mathrm{C}_{\mathrm{cs}, \mathrm{i}, \mathrm{j}}^{\mathrm{Capf}}+\mathrm{C}_{\mathrm{cs}, \mathrm{i}, \mathrm{j}}^{\mathrm{Capo}}\right) \mathrm{E}_{\mathrm{cs}, \mathrm{i}} \mathrm{y}_{\mathrm{cs}, \mathrm{i}, \mathrm{j}}
\end{aligned}
$$

Where:

$\mathrm{C}_{\mathrm{cs}, \mathrm{i}}^{\mathrm{Eop}}=$ Represents the operating cost coefficient of a boiler i at a coal power station cs

$\mathrm{C}_{\mathrm{cs}, \mathrm{i}, \mathrm{j}}^{\mathrm{Capp}}=$ Gives the fixed cost coefficient of a capture process $j$ on a boiler $i$ at a coal power station cs $\mathrm{C}_{\mathrm{cs}, \mathrm{ij}}^{\mathrm{Capo}}=$ Stands for the operating cost coefficient of a capture process $\mathrm{j}$ on a boiler $\mathrm{i}$ at a coal power station cs

The first term in the objective function represents the operating cost of coal plants. The second and third terms give the fixed and operating costs of the capture processes, respectively.

There are several constraints that limit the feasibility of the power generation network. Every boiler $i$ has a maximum production design capacity $E_{c s, i}^{\max }$ that should not be exceeded during operation as follows:

$$
\mathrm{E}_{\mathrm{cs}, \mathrm{i}} \leq \mathrm{E}_{\mathrm{cs}, \mathrm{i}}^{\max }
$$

It can also be stated that the maximum feasible electricity production from a given coal-fired power network cannot exceed the maximum electricity production design limits of all power plants:

$$
\sum_{c s} \sum_{i} E_{c s, i} \leq \sum_{c s} \sum_{i} E_{c s, i}^{\max }
$$

Constraint 3 defines the maximum throughput of the coal-fired power plants network. In another word, the model will declare infeasibility if the electricity demand is higher than the sum of the maximum electricity production capacity of the network.

Since the electricity demand, D, is a fixed value that should be satisfied, the model will optimize the electricity generation from all coal power plants (e.g., fuel balancing) to satisfy the electricity needs:

$$
\sum_{\mathrm{cs}} \sum_{\mathrm{i}} \mathrm{E}_{\mathrm{cs}, \mathrm{i}} \geq \mathrm{D}
$$

Environmental constraints on every pollutant, k, should comply with the maximum allowable limits that are set up by the environmental regulations as follows:

$$
\sum_{\mathrm{cs}} \sum_{\mathrm{i}} \mathrm{F}_{\mathrm{cs}, \mathrm{i}, \mathrm{k}}^{\mathrm{R}} \leq \mathrm{F}_{\mathrm{k}}^{\max } \quad \forall \mathrm{k}
$$

where $\mathrm{F}_{\mathrm{cs}, \mathrm{R}, \mathrm{k}}^{\mathrm{R}}$ stands for the flow of pollutant $\mathrm{k}$ that is released from boiler $\mathrm{i}$ at power station station cs. $\mathrm{F}_{\mathrm{k}}^{\max }$ represents a threshold limit of a pollutant $\mathrm{k}$ release to the atmosphere.

The role of capture processes is to reduce the total emissions release to the atmosphere. In the mathematical formulation, the binary variables $\mathrm{y}_{\mathrm{cs}, \mathrm{i}, \mathrm{j}}$ are related to the amount of pollutants $\mathrm{F}_{\mathrm{cs}, \mathrm{i}, \mathrm{j}, \mathrm{k}}^{\mathrm{CAP}}$ that are captured in the process as follows:

$$
\mathrm{F}_{\mathrm{cs}, \mathrm{i}, \mathrm{j}, \mathrm{k}}^{\mathrm{CAP}} \leq \mathrm{F}_{\mathrm{k}, \mathrm{j}}^{\mathrm{CAP}-\mathrm{max}} \mathrm{y}_{\mathrm{cs}, \mathrm{i}, \mathrm{j}} \quad \forall \mathrm{cs}, \mathrm{i}, \mathrm{j}, \mathrm{k}
$$

$\mathrm{F}_{\mathrm{k}, \mathrm{j}}^{\text {CAP-max }}$ gives an upper bound on the amount of pollutant $\mathrm{k}$ that can be captured with the capture process $\mathrm{j}$. Equation 6 defines the existence of a capture process $\mathrm{j}$. Mass balance for every pollutant $\mathrm{k}$ at every boiler $\mathrm{i}$ in a station cs can be described as;

$$
\mathrm{F}_{\mathrm{cs}, \mathrm{i}, \mathrm{k}}=\mathrm{F}_{\mathrm{cs}, \mathrm{i}, \mathrm{k}}^{\mathrm{R}}+\sum_{\mathrm{j}} \mathrm{F}_{\mathrm{cs}, \mathrm{i}, \mathrm{j}, \mathrm{k}}^{\mathrm{CAP}} \quad \forall \mathrm{cs}, \mathrm{i}, \mathrm{k}
$$

In this study, the emission of every pollutant $\mathrm{k}$ is related to the electricity produced at every boiler $\mathrm{E}_{\mathrm{cs}, \mathrm{i}}$ as:

$$
\mathrm{F}_{\mathrm{cs}, \mathrm{i}, \mathrm{k}}=\alpha_{\mathrm{k}} \mathrm{E}_{\mathrm{cs}, \mathrm{i}} \quad \forall \mathrm{cs}, \mathrm{i}, \mathrm{k}
$$

where, $\alpha_{\mathrm{k}}$ represents proportional constant between the electricity produced and the emission of pollutant $\mathrm{k}$ at a 
boiler i. Eq. 1-2, 4-8 give a nonconvex MINLP model of the coal-fired power plants network. The nonconvex terms in the objective function produce bilinear functions as a result of a multiplication of a binary variable, $\mathrm{y}_{\mathrm{cs}, \mathrm{i}, \mathrm{j}}$, with a continuous variable $\mathrm{E}_{\mathrm{cs}, \mathrm{j}}$. The problem can be reformulated to give convex mathematical program through the introduction of additional variables and constraints as follows:

$$
\begin{aligned}
& \eta_{c s, i, j}=E_{c s, i} y_{c s, i, j} \\
& 0 \leq \eta_{c s, i, j} \leq E_{c s, i} \\
& E_{c s, i}-M\left(1-y_{c s, i, j}\right) \leq \eta_{c s, i, j} \leq M y_{c s, i, j}
\end{aligned}
$$

Equation 9 replaces the nonconvex term in the objective function by a continuous variable, $\eta_{\mathrm{cs}, \mathrm{i}, \mathrm{j}}$. If the binary variable, $\mathrm{y}_{\mathrm{cs}, \mathrm{i}, \mathrm{j}}$, has a value of one, then Equation 10-11 insures that the value of the continuous variable $\eta_{\mathrm{cs}, \mathrm{i}, \mathrm{j}}$ matches the electricity produced $\mathrm{E}_{\mathrm{cs}, \mathrm{j}}$. On the other hand, if the binary variable, $\mathrm{y}_{\mathrm{cs}, \mathrm{i}, \mathrm{j}}$, has zero value, then Eq. 10-11 forces the continuous variable $\eta_{\mathrm{cs}, \mathrm{i}, \mathrm{j}}$ value to have zero value. $M$ represents a big number value. Therefore, the set of Eq. 1-2, 4-11 gives an MILP model for the coal power plant network.

Case study: Ontario Power Generation (OPG) operates five coal-fired power stations: Lambton (L), Nanticoke (N), Lakeview (LV), Atikokan (A) and Thunder Bay (TB). Lambton has four boilers, Nanticoke has eight boilers, Lakeview has eight boilers, Atikokan has one and Thunder Bay has two boilers. Therefore, twenty three coal-fired boilers correspond to sources of $\mathrm{SO}_{\mathrm{x}}$, NOx and $\mathrm{Hg}$ emissions.

There are several pollution abatement technologies that can be used to control the $\mathrm{NO}_{\mathrm{x}}$ emissions. Selective Catalytic Reduction (SCR) process involves converting $\mathrm{NO}_{\mathrm{x}}$ with the aid of a catalyst into nitrogen and water in the presence of oxygen. Selective Non-Catalytic Reduction (SNCR) process involves injecting either ammonia or urea into the firebox of the boiler at high temperature locations (e.g., 1600-2100 ${ }^{\circ} \mathrm{F}$ ). It then reacts with the nitrogen oxides formed in the combustion process to produce nitrogen, carbon dioxide and water. Coal Re-burning (CR) technology is a process to condition the coal (pulverized coal) before the combustion process.

Wet Flue Gas Desulfurization (WFGD) process involves scrubbing $\mathrm{SO} 2$ by using alkaline slurry made by adding lime $(\mathrm{CaO})$ to water. The alkaline slurry is sprayed into the exhaust stream and reacts with $\mathrm{SO}_{2}$.
Insoluble sulfur salts form as a solid by-product. Dry Flue Gas Desulfurization (DFGD) process consists of the atomization of a alkaline reagent slurry via rotary atomizers or pneumatic nozzles. It is then injected into a vessel where it reacts with the $\mathrm{SO}_{2}$ in the flue gas to produce sulfate products. Flue gas exiting the spray dryer is directed into Electro Static Precipitator (ESP) to collect the dry material or partially introduced to an absorber with a slurry mixture to enhance the overall efficiency of the process.

Activated Carbon Injection (ACI) with particulate control (e.g., ESP) involves the injection of activated carbon powder into the flue gas stream. Vapor phase $\mathrm{Hg}$ is adsorbed onto the activated carbon which is then collected in the ESP. WFGD with mercury oxidation controls the emission of two pollutants, $\mathrm{SO}_{2}$ and $\mathrm{Hg}$. Reagent-based oxidants can be injected in the flue gas or in the WFGD scrubber to promote $\mathrm{Hg}$ oxidation. These technologies of $\mathrm{NO}_{\mathrm{x}}, \mathrm{SO}_{\mathrm{x}}$ and $\mathrm{Hg}$ are adopted in the mathematical programming formulation by including several capture processes over every boiler in order to reduce the boiler emissions.

The scenario covered in this study will focus on:

- Optimization an actual base case to find out the optimal generation from the coal-fired power plant in order to satisfy the electricity demand and emission constraints. This is accomplished by fuel balancing and capture processes mitigations

- Optimization the coal power plants to achieve increased electricity demand with reduction targets of 10,20 and $30 \%$ for every pollutant from the actual base case

The first point addresses the correction or adjustment of current production of electricity from the coal power plants. The second scenario addresses reduction targets that can be implemented within the network to satisfy future electricity demand with emission restrictions.

Current electricity production from OPG coal power plants is shown in Fig. 2. As shown by the Fig. 2 , not all boilers generate the same amount of electricity to the grid. For instance, L1 and L2 boilers generate 3,242,295 MWh year $^{-1}$, while L3 and L4 generate $1,768,705 \mathrm{MWh}$ year $^{-1}$. It is important to note that the electricity generation from these plants is below their maximum design production limits. For the current OPG operation, the coal-fired boilers emit 3,593 ton year ${ }^{-1}$ of $\mathrm{NO}_{\mathrm{x}}, 23,833$ ton year ${ }^{-1}$ of $\mathrm{SO}_{\mathrm{x}}$ and 0.0561 ton year $^{-1}$ of $\mathrm{Hg}$. The total cost to run these plants was found to be $\$ 755,936,730$ year $^{-1}$ for a total electricity production of $36,946,00 \mathrm{MWh}$ year $^{-1}$. This situation will be the base case of the current study. 
Am. J. Engg. \& Applied Sci., 1 (4): 358-367, 2008

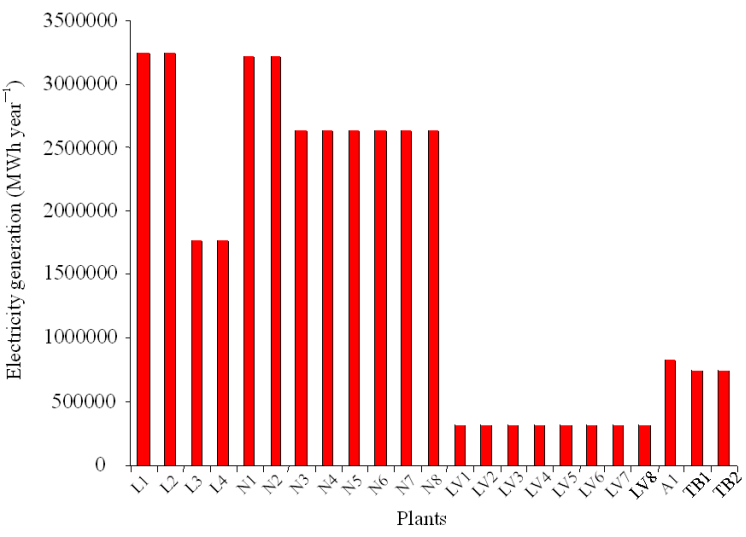

Fig. 2: OPG current electricity generation by coal plants

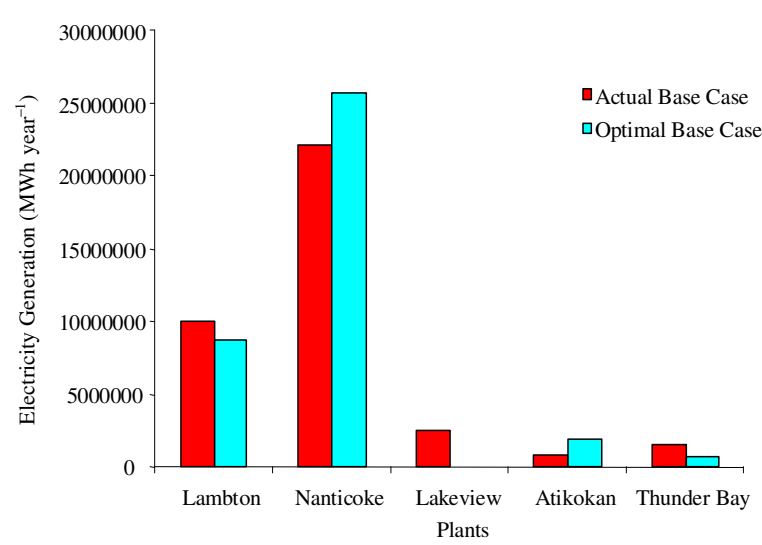

Fig. 3: Optimal operation for the base case scenario

Fuel balancing is an important approach to reduce the pollutant releases to the atmosphere. In other words, while minimizing the objective function, the optimizer tries to seek an improved production plans from the power network to satisfy the electricity demand and choose the power plants with the least pollutant emissions. The results show that the total cost was reduced by $3 \%$ through decreasing the electricity from Lambton, Lakeview and Thunder Bay, while increasing the generation from Nanticoke and Atikokan power stations. Figure 3 shows the optimal generation from the coal power stations.

Table 1 indicates that only boilers L3, L4, N1, N3, $\mathrm{N} 5$ to $\mathrm{N} 8, \mathrm{~A} 1$ and $\mathrm{TB} 2$ are generating electricity to the grid. Besides, other boilers are shut down from operation. Despite specifying 0\% reduction of pollutant emissions, as a result of fuel balancing and control technologies, $6.2 \%$ reduction of $\mathrm{SO}_{\mathrm{x}}$ was still achieved. Additionally, $38.4 \%$ reduction of $\mathrm{Hg}$ was achieved as a result of fuel balancing. From Table 2 it can be shown that $\mathrm{NO}_{\mathrm{x}}$ control technologies (Coal re-burners) are
Table 1: Optimal electricity generation for the base case

\begin{tabular}{|c|c|c|c|c|}
\hline \multirow[b]{2}{*}{ Boilers } & \multirow[b]{2}{*}{ Optimal base case } & \multicolumn{3}{|c|}{ Reduction targets } \\
\hline & & $10 \%$ & $20 \%$ & $30 \%$ \\
\hline$\overline{\mathrm{L} 1}$ & 0 & • & o & • \\
\hline L2 & 0 & o & o & o \\
\hline L3 & - & - & - & - \\
\hline L4 & - & - & - & o \\
\hline N1 & - & - & - & o \\
\hline $\mathrm{N} 2$ & 0 & - & - & - \\
\hline N3 & - & - & - & - \\
\hline $\mathrm{N} 4$ & o & o & - & - \\
\hline N5 & - & - & o & - \\
\hline N6 & - & - & - & o \\
\hline N7 & - & o & o & - \\
\hline N8 & - & - & - & - \\
\hline LV1 & 0 & o & o & o \\
\hline LV2 & 0 & $\mathrm{o}$ & $\mathrm{o}$ & o \\
\hline LV3 & 0 & o & o & o \\
\hline LV4 & o & o & o & - \\
\hline LV5 & 0 & - & - & - \\
\hline LV6 & o & o & o & o \\
\hline LV7 & 0 & o & o & - \\
\hline LV8 & 0 & $\mathrm{o}$ & o & o \\
\hline A1 & - & - & - & - \\
\hline TB1 & 0 & - & o & - \\
\hline TB2 & - & - & - & o \\
\hline
\end{tabular}

Note: ‘`’ Electricity generation, 'o’ No electricity generation

Table 2: Optimal control technologies installation for the base case scenario

\begin{tabular}{|c|c|c|c|}
\hline \multirow[t]{2}{*}{ Boilers } & \multicolumn{3}{|c|}{ Optimal base case } \\
\hline & $\mathrm{NO}_{\mathrm{x}}$ & $\mathrm{SO}_{\mathrm{x}}$ & $\mathrm{Hg}$ \\
\hline$\overline{\mathrm{L} 1}$ & o & o & o \\
\hline L2 & o & o & o \\
\hline L3 & o & o & o \\
\hline L4 & - & o & o \\
\hline N1 & o & o & o \\
\hline $\mathrm{N} 2$ & o & $\mathrm{o}$ & o \\
\hline N3 & - & o & o \\
\hline N4 & o & o & o \\
\hline N5 & - & o & o \\
\hline N6 & o & - & o \\
\hline N7 & - & o & o \\
\hline N8 & o & - & o \\
\hline LV1 & o & o & o \\
\hline LV2 & o & o & o \\
\hline LV3 & o & o & o \\
\hline LV4 & o & o & o \\
\hline LV5 & o & o & o \\
\hline LV6 & o & o & o \\
\hline LV7 & o & o & o \\
\hline LV8 & o & o & o \\
\hline A1 & o & o & o \\
\hline TB1 & o & o & o \\
\hline TB2 & o & o & o \\
\hline
\end{tabular}

Note: '•' Control technology, 'o' No control technology

installed on boilers L4, N3, N5 and N7, while $\mathrm{NO}_{\mathrm{x}}$ control technologies (spray dry absorbers) are installed on boilers N6 and N8.

The first reduction target was set for $10 \%$ reduction of $\mathrm{NO}_{\mathrm{x}}, \mathrm{SO}_{\mathrm{x}}$ and mercury to obtain a minimized cost 


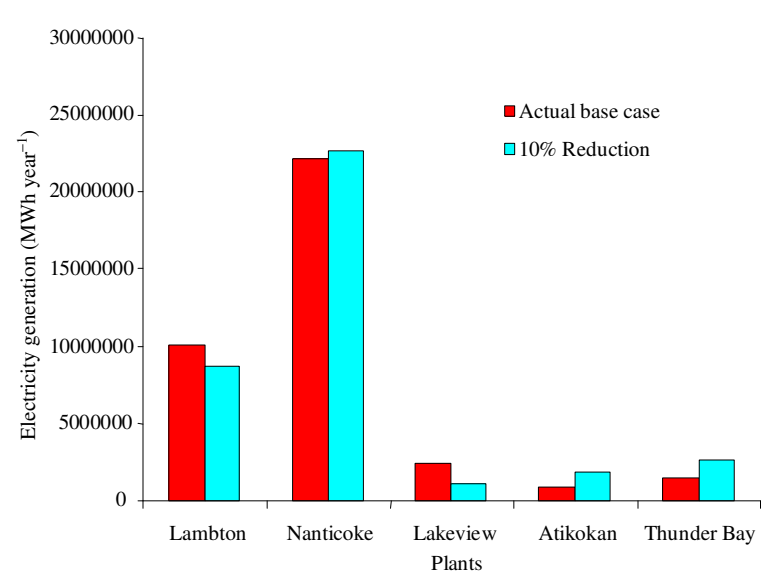

Fig. 4: Optimal operation of OPG network under 10\% reduction target

for optimal electricity generation while meeting electricity demand. These results can be shown in Fig. 4. Fuel balancing was implemented by increasing load from boilers that emit less emissions and decreasing load from boilers that emit more. For this scenario, it was found that the total cost was reduced by $1.51 \%$, in which electricity generation was decreased from Lambton and Lakeview, while generation was increased from Nantikoke, Thunder Bay and Atikokan. The total electricity generation was found to be 36,946,007MWh year ${ }^{-1}$.

From Table 1 it can be seen that boilers L1, L3, L4, N1, N2, N3, N5, N6, N8, LV5, A1, TB1 and TB2 are generating electricity to the grid, while all other boilers are shut down from operation. For an overall 10\% reduction target of pollutant emissions, $9.93 \%$ reduction of $\mathrm{NO}_{\mathrm{x}}$ and $10.07 \%$ reduction of $\mathrm{SO}_{\mathrm{x}}$ were achieved as a result of fuel balancing and control technologies. Furthermore, $39.3 \%$ reduction of mercury was achieved as a result of fuel balancing. Table 3 indicates that for $\mathrm{NO}_{\mathrm{x}}$ control technologies, coal re-burners are installed on boilers L4, N1, N3, N5 and N6 while the SCR process was installed on boiler $\mathrm{L} 1$. For $\mathrm{SO}_{\mathrm{x}}$ control technologies, spray dry absorbers are installed on boilers $\mathrm{N} 2$ and $\mathrm{A} 1$ while the advanced dry flue gas desulfurization process is installed on boilers LV5, TB1 and TB2.

The results for the minimized cost for optimal electricity generation while maintaining electricity demand at a $20 \%$ reduction target of $\mathrm{NO}_{\mathrm{x}}, \mathrm{SO}_{\mathrm{x}}$ and mercury can be shown in Fig. 5. Fuel balancing was implemented again by increasing load from boilers that emit less emissions and decreasing load from boilers that emit more. For this scenario, it was found that the total cost was increased by $0.92 \%$ by decreasing

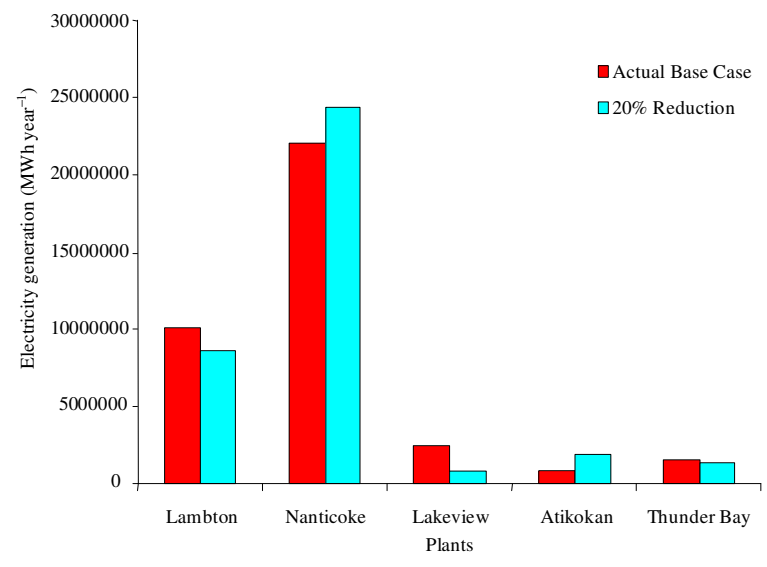

Fig. 5: Optimal operation of OPG network under 20\% reduction target

Table 3: Optimal control technologies installation for the case of $10 \%$ reduction of emissions

\begin{tabular}{|c|c|c|c|}
\hline \multirow[t]{2}{*}{ Boilers } & \multicolumn{3}{|c|}{$10 \%$ reduction } \\
\hline & $\mathrm{NO}_{\mathrm{x}}$ & $\mathrm{SO}_{\mathrm{X}}$ & $\mathrm{Hg}$ \\
\hline$\overline{\mathrm{L} 1}$ & $\bullet$ & 0 & o \\
\hline L2 & o & o & o \\
\hline L3 & o & o & o \\
\hline $\mathrm{L} 4$ & $\bullet$ & o & o \\
\hline N1 & • & o & o \\
\hline N2 & o & • & o \\
\hline N3 & • & o & o \\
\hline N4 & o & o & o \\
\hline N5 & $\bullet$ & o & o \\
\hline N6 & • & o & o \\
\hline N7 & o & o & o \\
\hline N8 & o & o & o \\
\hline LV1 & o & o & o \\
\hline LV2 & o & o & o \\
\hline LV3 & o & o & o \\
\hline LV4 & o & o & o \\
\hline LV5 & o & $\bullet$ & o \\
\hline LV6 & o & o & o \\
\hline LV7 & o & o & o \\
\hline LV8 & o & o & o \\
\hline A1 & o & • & o \\
\hline TB1 & o & • & o \\
\hline TB2 & $\mathrm{o}$ & • & o \\
\hline
\end{tabular}

Note: ‘’ Control technology, 'o' No control technology

electricity generation from Lambton, Lakeview and Thunder Bay while increasing generation from Nantikoke and Atikokan. The total electricity generation was found to be $36,945,980 \mathrm{MWh}$ year $^{-1}$.

Table 1 indicates that only boilers L3, L4, N1, N2, $\mathrm{N} 3, \mathrm{~N} 4, \mathrm{~N} 6, \mathrm{~N} 8, \mathrm{LV} 5, \mathrm{~A} 1$ and TB2 are generating electricity to the grid, while all other boilers are shut down from operation. For an overall 20\% reduction target of pollutant emissions, $19.94 \%$ reduction of $\mathrm{NO}_{\mathrm{x}}$ and $20.07 \%$ reduction of $\mathrm{SO}_{\mathrm{x}}$ was achieved as a result of fuel balancing and control technologies. Mercury 
Am. J. Engg. \& Applied Sci., 1 (4): 358-367, 2008

Table 4: Optimal control technologies installation for the case of $20 \%$ reduction of emissions

\begin{tabular}{|c|c|c|c|}
\hline Boilers & $\begin{array}{l}20 \% \\
\mathrm{NO}_{\mathrm{x}}\end{array}$ & $\mathrm{SO}_{\mathrm{X}}$ & $\mathrm{Hg}$ \\
\hline$\overline{\mathrm{L} 1}$ & o & o & 0 \\
\hline L2 & o & o & o \\
\hline L3 & • & o & o \\
\hline L4 & • & o & o \\
\hline N1 & • & o & o \\
\hline $\mathrm{N} 2$ & o & • & o \\
\hline N3 & • & o & o \\
\hline $\mathrm{N} 4$ & • & o & o \\
\hline N5 & o & o & o \\
\hline N6 & o & • & o \\
\hline N7 & o & o & o \\
\hline N8 & o & • & o \\
\hline LV1 & o & o & o \\
\hline LV2 & o & o & o \\
\hline LV3 & o & o & o \\
\hline LV4 & o & o & o \\
\hline LV5 & • & o & o \\
\hline LV6 & o & o & o \\
\hline LV7 & o & o & o \\
\hline LV8 & o & o & o \\
\hline $\mathrm{A} 1$ & o & • & o \\
\hline TB1 & o & o & o \\
\hline TB2 & • & o & o \\
\hline
\end{tabular}

Note: ‘’ Control technology, 'o' No control technology

was reduced by $44.6 \%$ as a result of fuel balancing. Table 4 indicates that for $\mathrm{NO}_{\mathrm{x}}$ control technologies, coal re-burners are installed on boilers L3, L4, N1, N3 and TB2 while the SCR process was installed on boilers $\mathrm{N} 4$ and LV5. For $\mathrm{SO}_{x}$ control technologies, a spray dry absorber is installed on boiler N6, advanced DFGD system is installed on boiler N2, a DFGD system is installed on boiler N8 and a WFGD system is installed on boiler A1.

For a reduction target of $30 \%$, the minimized cost and electricity generated by each boiler can be shown in Fig. 6. Fuel balancing was implemented whereby the total cost was increased by $10.38 \%$ by decreasing electricity generation from Lambton and Thunder Bay while increasing generation from Nantikoke, Lakeview and Atikokan. The total electricity generation was found to be $36,945,950 \mathrm{MWh} / \mathrm{yr}$.

From Table 1 it can be seen that boilers L1, L3, N2, N3, N4, N5, N7, N8, LV4, LV5, LV7, A1 and TB1 are generating electricity to the grid, while all other boilers are shut down from operation. For an overall $30 \%$ reduction target of pollutant emissions, $29.95 \%$ reduction of $\mathrm{NO}_{\mathrm{x}}, 30.06 \%$ reduction of $\mathrm{SO}_{\mathrm{x}}$ and $52.4 \%$ reduction of mercury was achieved as a result of fuel balancing and control technologies. Table 5 shows that for $\mathrm{NO}_{\mathrm{x}}$ control technologies, a coal re-burner is installed on boiler L3, while the SCR process was installed on boilers L1, N4, N8, LV4, LV5, LV7, A1 and TB1. The $\mathrm{SO}_{\mathrm{x}}$ control technologies consisted of a
Table 5: Optimal control technologies installation for the case of $30 \%$ reduction of emissions

\begin{tabular}{|c|c|c|c|}
\hline Boilers & \multicolumn{3}{|c|}{$30 \%$ Reduction } \\
\hline L1 & • & 0 & o \\
\hline L2 & o & o & o \\
\hline L3 & - & o & o \\
\hline L4 & o & o & o \\
\hline N1 & o & o & o \\
\hline N2 & o & - & - \\
\hline N3 & o & - & - \\
\hline N4 & - & o & o \\
\hline N5 & o & - & o \\
\hline N6 & o & o & o \\
\hline N7 & o & - & o \\
\hline N8 & - & o & o \\
\hline LV1 & o & o & o \\
\hline LV2 & o & o & o \\
\hline LV3 & o & o & o \\
\hline LV4 & - & $\mathrm{o}$ & o \\
\hline LV5 & - & o & o \\
\hline LV6 & o & o & o \\
\hline LV7 & - & $\mathrm{o}$ & o \\
\hline LV8 & o & o & o \\
\hline A1 & - & $\mathrm{o}$ & o \\
\hline TB1 & - & o & o \\
\hline TB2 & o & o & o \\
\hline
\end{tabular}

Note: ‘’ Control technology, 'o’ No control technology

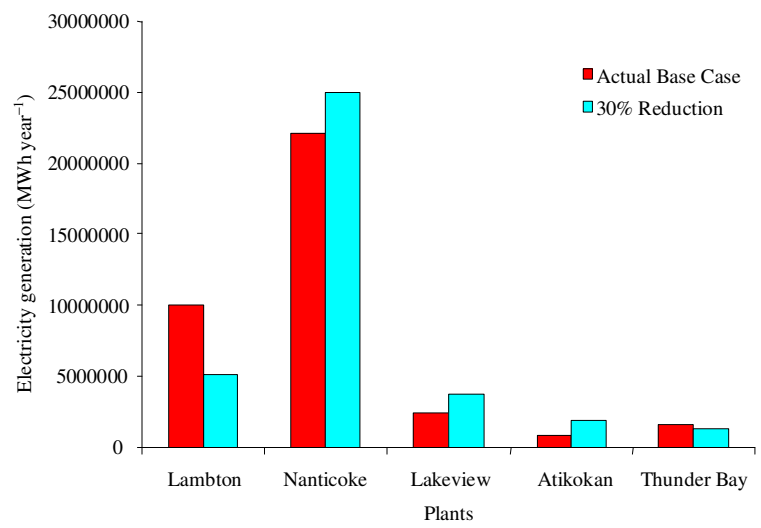

Fig. 6: Optimal operation of OPG network under 30\% reduction target

spray dry absorber is installed on boiler N7, advanced DFGD system is installed on boiler N5 and WFGD systems with mercury oxidation are installed on boilers N2 and N3. The WFGD systems with mercury oxidation were also installed on boilers $\mathrm{N} 2$ and $\mathrm{N} 3$ to reduce mercury emissions while also reducing $\mathrm{SO}_{\mathrm{x}}$.

Further investigation of the effect of electricity demand increase on the total cost to achieve a specific target was analyzed. $20 \%$ reduction of emissions from the base case is chosen as a reference for the electricity demand increase. The results show in general increase of the cost of electricity with increasing the demand up 


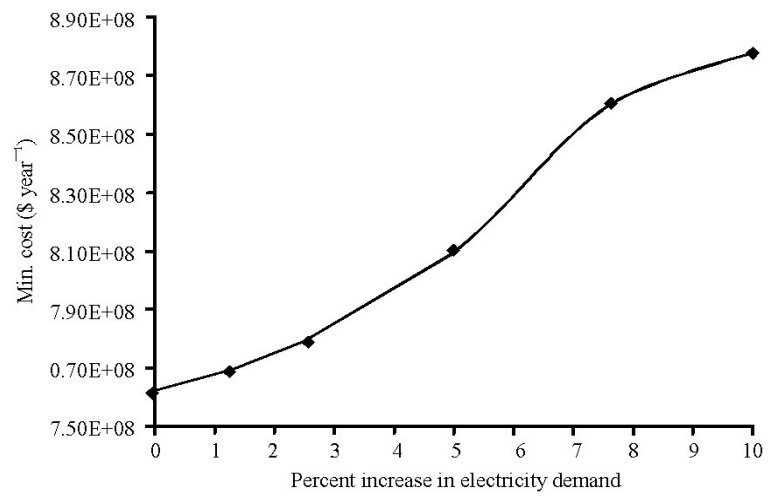

Fig. 7: Effect of the electricity demand increase on the overall cost of electricity production cost

to $10 \%$ from the base case, Fig. 7 . This is due to the increase of pollutant flow rate with increasing the production of electricity which requires more control technologies to satisfy the reduction targets.

\section{DISCUSSION}

In this study, optimal production planning of electricity from coal-fired power plants was analyzed with the view of emission capture and reduction while maintaining sufficient electricity demand. Fuel balancing and emission capture processes were two mitigation strategies to manage electricity production and control pollutant release to the atmosphere. Different scenarios of increasing electricity production and reduction targets of $\mathrm{NO}_{\mathrm{x}}, \mathrm{SO}_{\mathrm{x}}$ and $\mathrm{Hg}$ were undertaken to study their effects on the optimal production from a network of coal-fired power plants. A case study of Ontario Power Generation, OPG, was given as illustration of the proposed methodology.

The results show that considering the multipollutant problem from coal-fired power plants give more advantages over the single pollutant reduction case. Due to the differences in the emission release from the coal-fired power plants, optimal fuel balancing and capture processes give more reduction of these pollutants while satisfying electricity demand. Beside, the proposed approach can be extended to include other power generation technologies in order to meet the electricity demand and reduce the overall emission release.

The constraints of pollutant emissions from coal power plants will in general limit the electricity production. This in turn will bound electricity supply with increasing the demand of electricity. Renewable energy technologies such hydroelectric, wind power plants and nuclear plants emits almost zero emissions.
A future work will consider the integration of these technologies with coal power plant network in order to study their effects on the optimal operation of coal power plant network.

\section{ACKNOWLEDGMENT}

The authors wish to thank KFUPM Saudi Arabia, UW for their support.

\section{REFERENCES}

1. Topper, J., P. Cross and S. Goldthrope, 1994. Clean coal technology for power and cogeneration. Fuel, 73: 1056 - 1063. DOI: 10.1016/00162361(94)90237-2.

2. Herzog, H. and J. Katzer, 2006. The future of coal in a greenhouse gas constrained world. Proceedings of the 8th International Conference on Greenhouse Gas Control Technologies, Trondheim, Norway, June 19-22, $1-6$. http://sequestration.mit.edu/pdf/GHGT8_Herzog_ Katzer.pdf.

3. George, A. and R. Kandiyoti, 2008. Thermochemical reactor design and thermal breakdown in middle-rank coals. Int. J. Oil Gas Coal Technol., 1: 308-329. DOI: 10.1504/IJOGCT.2008.019847.

4. Sekar R., J. Parsons, H. Herzog and H. Jacoby, 2007. Future carbon regulations and current investments in alternative coal-fired power plant technologies. Energ. Policy, 35: 1064-1074.DOI: 10.1016/j.enpol.2006.01.020.

5. He, B., Y. Cao, C.E. Romero, H. Bilirgen, H., N. Sarunac, H. Agarwal, and W.P. Pan, 2007. Comparison and validation of OHM and SCEM measurements for a full-scale coal-fired power plant, Chemical Engineering Communications, 194: 1596-1607. DOI:

10.1080/00986440701432268

6. Rubin, E., A. Rao and C. Chen, 2004. Comparative assessments of fossil fuel power plants with $\mathrm{CO}_{2}$ capture and storage. Proceedings of the $7^{\text {th }}$ International Conference on Greenhouse Gas Control Technologies, Sept. 5-9, Vancouver, Canada, pp: 285-293. http://uregina.ca/ghgt7/PDF/papers/peer/475.pdf.

7. Rubin, E., A. Rao and M. Berkenpas, 2001. A multi-pollutant framework for evaluating $\mathrm{CO}_{2}$ control options for fossil fuel power plants. Proceeding of the 1st National Conference on Carbon Sequestration, Washington D.C., USA, May 15-17, pp: 1-17. http://www.netl.doe.gov/publications/proceedings/ 01/carbon_seq/2c2.pdf. 
8. Miller, M.J., 2006. Retrofit $\mathrm{SO}_{2}$ and $\mathrm{NO}_{\mathrm{x}}$ control technologies for coal-fired power plants, Environ. Progress, 5: 171-177. DOI: 10.1002/ep.670050311.

9. Mathur, R., S. Chand and T. Tezuka, 2003. Optimal use of coal power generation in India. Energy Policy, 31: 319-331. DOI: 10.1016/S03014215(02)00067-8.

10. Johnson, T. and D. W. Keith, 2004. Fossil electricity and $\mathrm{CO}_{2}$ sequestration: how natural gas prices, initial conditions and retrofits determine the cost of controlling $\mathrm{CO}_{2}$ emissions. Energ. Policy, 32: 367-382. http://cat.inist.fr/?aModele $=$ afficheN\&cpsidt $=1511$ 5849.

11. Wise, M. and J.J. Dooley, 2004. Baseload and peaking economics and the resulting adoption of a carbon dioxide capture and storage system for electric power plants. Proceeding of the 7th International Conference on Greenhouse Gas Emissions, Sept. 5-9, Vancouver, Canada, pp: 110.

12. Narula, R.G., H. Wen, K. Himmes and B. Power, 2002. Incremental cost of $\mathrm{CO}_{2}$ reduction in power plants. Proceeding of IGTI ASME turbo EXPO, June 3-6, Amsterdam, Netherlands, pp. 1-10. http://www.bechtel.com/assets/files/PDF/BIP/2305 7.pdf.

13. Rubin, E.S., C. Chen and A.B. Rao, 2007. Cost and performance of fossil fuel power plants with $\mathrm{CO}_{2}$ capture and storage. Energ. Policy, 35: 4444-4454. DOI: 10.1016/j.enpol.2007.03.009.
14. Ba-Shammakh, M., A. Elkamel, P. Douglas, E. Croiset, 2007. A mixed-integer non-linear programming model for $\mathrm{CO}_{2}$ emission reduction in the power generation sector. Int. J. Environ. Pollut., 29: 254-273. DOI: 10.1504/IJEP.2007.012806.

15. Hashim, H., P. Douglas, A. Elkamel and E. Croiset, 2005. Optimization Model for Energy Planning with $\mathrm{CO}_{2}$ Emission Considerations, Ind. Eng. Chem. Res., 44: 879-890. DOI: 10.1021/ie049766o.

16. Liu, Z.F., G.H. Huang and N. Li, 2008. A dynamic optimization approach for power generation planning under uncertainity. Energy Sources, Part A: Recovery, Utilization Environ. Effects, 30: 1413-1431. DOI: 10.1080/15567030801929217.

17. Yokoyama, R., Y. Hasegawa and K. Ito 2002. A MILP decomposition approach to large scale optimization in structural design of energy supply systems. Energ. Conversion Manage., 43: 771-790. DOI: 10.1016/S0196-8904(01)00075-9

19. Antunes, C.H., A.G. Martins and I.S. Brito, 2004. A multiple objective mixed integer linear programming model for power generation expansion planning. Energy, 29: 613-627. DOI: 10.1016/j.energy.2003.10.012.

20. Linares, P. and C. Romero, 2002. Aggregation of preferences in an environmental economics context: A goal programming approach. Omega, 30: 89-95. DOI: 10.1016/S0305-0483(01)00059-7. 